\title{
BIM 技术对全过程工程造价控制的影响
}

黄莹

中冶华天工程技术有限公司

DOI:10.18686/bd.v2i9.1641

[摘 要] 现阶段,BIM 技术在造价控制中得到了十分广泛的应用, 因此建筑造价控制及管理人员应详细了解并熟练掌握 BIM 技术,使其能够更好的推动整个建筑行业的建设与发展。

[关键词] BIM 技术; 造价控制; 管理; 建筑行业

现阶段, 我国的工程造价管理工作虽然在不断发展和 完善, 但在工程造价控制工作中依然存在着较为明显的问 题。科学应用 BIM 技术可建立更为完善的工程信息数据模 型,同时结合模型的数据信息,对工程项目建设的整个过程 进行科学计价和估价,保证工程造价的科学性及合理性。

\section{BIM 技术概述}

BIM 技术又叫建筑信息模型, 这一技术最初的定义是 对项目物理特性及功能特性的数字化表达。BIM 技术需要 多个环节的协同工作, 其可借助对各阶段参建方在模型当 中所录人的信息, 为项目概念的提出到全生命周期的决策 提供全面且可靠的依据。此外, 其在运行的过程中将数据作 为核心,在计算机科技平台的支持下保证信息的高度共享。 加之该技术可将工程信息和业务信息紧密地结合在一起, 并采取了有效的全过程管理举措, 从而保证工程量计算的 科学性及准确性。

\section{BIM 技术的发展背景分析}

现如今, 建筑工程造价已经处于全过程管理和控制的 状态, 在实际的工作中, 主要的压力来自于风险管理与成本 管理。以往的造价管理和控制模式已经无法顺应当今时代 的发展要求, 现如今工程造价控制已经朝着全过程精准造 价管理的方向发展。建筑工程造价控制的质量与工程基础 数据信息之间有着千丝万缕的联系, 故而要想做到数据信 息的准确性与及时性, 就需管理者提高工程基础数据信息 的信息化及智能化水平, 以此减少时间成本及经济成本。而 这一发展方向也为工程造价控制工作提出了更为严格的要 求,而这也是 BIM 技术出现的重要原因。

\section{BIM 技术对全过程造价控制的影响}

3.1 项目投资决策阶段的影响

在项目投资决策当中, 确定科学的投资方案对工程造 价有着十分重要的影响。在工程建设的前期其所起到的作 用也十分明显。管理者应针对不同的建设项目,制定针对性 的施工方案。在传统的建设方案技术和经济比较过程中,通 常采用经验判断、方案评分和经济计算等方式。其中经验判 断法主要是利用经验和实践操作技术, 来完成工程的建设 与施工。这种方式的实用性较强, 对决策也有一定的推动作 用。但是从整体上来说, 这一技术无法保证规划的科学性, 在
投资方面没有充足的数据支持,因此风险性较大。而方案评 分法则主要是依据方案中的数据进行工程的建设与施工, 其可有效辨别工程方案的质量,分析其可行性,但是这种方 式的主观性较强, 客观性不足。经济计算法主要是借助项目 的数据完成统计与策划工作, 这种方式具有较强的科学性 及准确性,但是其效率较低,需要投人较大的时间成本。

利用 BIM 技术能够将不同的方案以 $3 \mathrm{D} 、 4 \mathrm{D}$ 或 $5 \mathrm{D}$ 的 方式, 来完成项目的虚拟构建, 且项目建设的全过程及建成 后的效果会以最为清晰和直观的形式展示给有关工作人 员,从而为优选方案提供了较大的便利。另外建设单位应根 据设计院所提供的设计方案, 在充分考虑多个因素的影响 后, 再对时间和成本因素进行科学分析, 这样才能选出最优 方案。

项目投资会在很大程度上受到项目决策与规划的影 响,在项目施工的过程中,应科学规划投资的方向,从而有效 保证投资的效益。其可提高工程造价与控制的主动性, 使经 济与技术能够得到更为全面地融合。并且其还可有效指导 建设单位的资金评估、限额设计等多个环节。同时将 BIM 技术应用在工程造价管理控制中,也能提高投资回报, 降低 投资成本, 最终有效提高工程造价管理与控制的质量及水 平。

\section{2 项目投资实施阶段的影响}

为了全方位的确保工程设计的科学性及合理性, 在项 目投资实施阶段应用 BIM 技术有着十分积极的意义。设计 单位借助模型开展物理碰撞与规则碰撞的检查工作, 以及 时发现设计图纸当中的不足, 并根据具体问题合理解决由 于设计不合理或修改设计而带来的不利影响, 所以说其对 设计方案的整改以及工程施工条款的确定都有着不可忽视 的作用。另外该技术还可为项目前期招标工作提供更为科 学和全面的招标文件, 通过该项管理提高招标工作的质量 和效率,最大限度降低工程竣工结算的工作强度。

此外, 工程实施是造价控制中最容易出现问题的环节, 其具有较强的复杂性,工作难度较大。且其中工程变更和索 赔是重难点。应用 BIM 技术在前期决策时就开展了模拟建 设, 可及时发现工程设计和施工中存在的不足, 并采取针对 性的整改措施。加之该技术不但提高了设计的科学性, 也提 
高了工作效率。施工单位利用 BIM 技术能够科学安排施工 工序, 合理调配资金,且加强资金与材料的管理力度。再者 BIM 技术还能加强材料和资金管理的有效性, 进而降低成 本投人。而且管理者采取科学的控制方式能够对项目的投 资建设创造更加优良的条件, 这对提高工程经济效益也有 着较为重要的意义。

\section{3 项目竣工结算与后评估阶段}

因为 BIM 技术在科研和立项阶段就已经进行了造价 控制工作,所以,结算阶段的工作量明显减少。在这一过程中 咨询服务相对较多,如竣工图纸的审核、统计工程变更联系 单、完成工程造价计算、全面审核承包商的合同内容、审核 承包商所提交的工程竣工结算书及完成对账工作后应递交 结算的审核报告等。

在项目评后评价的过程中, 因为项目所有数据都输人 到了 BIM 模型当中, 因此多种经济指标能够利用计算机完 成所有的计算和输出工作,将信息数据制成表格,实现信息 化办公。另外采用创建的数据模型对工程的建设质量进行 分析和总结, 可为日后的工程建设及造价管理提供更多具 有参考价值的经验。可以说 BIM 技术可应用在项目运行的 整个生命周期之中,且在不同阶段发挥着不同的作用。

BIM 技术在应用过程中冲破了以往工作模式的束缚, 在项目设计、施工和运行的过程中能够充分考虑其特点,传 统的经营和运行方式都得到了极大的转变, 真正地实现了 精细化管理。这一技术能够对建筑的质量、进度和成本信息 进行科学管理及控制。实现了项目的模拟建设,可在可视化 的条件下完成管理工作。另外,其还能有效提高文件的质量, 减少管理过程中的成本投人,最终扩大信息共享的范围。

\section{4 案例分析}

4.1 工程概况

某项目工程在设计的过程中应用 BIM 碰撞检测技术, 在检测的过程中发现了 70 多处管道穿墙预留套管高度不 符合设计要求的问题,同时还发现并调整了 30 多处楼板大 小预留洞口的问题, 楼梯间加压百叶窗和墙体预留的消火 栓 20 多处,幕墙建筑大小和百叶的设置与实际应用不适应 的问题达 30 多处,共处理了近 3000 个问题,减少了工程的 成本投人。通过上述分析我们也可以明确 BIM 技术可有效 提高成本管理和造价控制的质量和效率。

4.2 加大工程信息共享力度,提高信息的透明度

BIM 模型当中涵盖了建筑生产中所产生的所有信息,
其本身就是一个庞大的数据库, 数据库中储存了工程不同 阶段的详细信息, 同时其也能够为工程造价控制提供更为 全面及可靠的依据, 且在各管理部门之间能够更好地实现 信息的共享,增强了信息的透明度,有利于解决参建各方在 工程量方面产生的纠纷, 有效避免参建方隐瞒工程量的问 题。

\section{3 提高了获取工程量信息的准确性与快捷性}

BIM 模型中可直接读取工程量, 大大减轻了造价人员 的工作强度,而这一工作主要由设计人员完成。在建模期间, 设计人员需对添加的构件属性予以定义, 明确构件的材质 及规格。而在完成建模环节后, 工程量也会随之明显减少。

4.4 实现了全面的成本控制

建立科学统一的信息模型能够将工程参建各方聚集在 同一个平台上, 参建各方能够从自身的专业出发, 对工程成 本控制工作提出有针对性的意见和检疫, 这一转变大大提 高了成本管理与控制的质量及水平。此外,其还可解决不同 专业之间的矛盾和冲突。BIM 模型可及时汇总施工中的问 题和不足,并针对问题采取有效的解决措施。可以说 BIM 技 术的应用使参建各方构成了一个较为完整的整体，提高了 项目管理的有效性, 同时资源利用效率也得以明显改善,起 到了防范投资风险的作用。

\section{5 结束语}

当前在建筑工程施工建设中, 工程造价的管理及控制 是不可忽视的一环, 而 BIM 技术在很多建筑企业都得到了 广泛的应用,其在工程造价控制上的作用也日益突显出来。 在工程的整个生命周期,BIM 技术占据着非常重要的位置, 其可有效减少成本投人, 在提高资源利用率和工程建设效 率的基础上,也加大了企业的经济效益,促进了企业的健康 长远发展。

\section{[参考文献]}

[1]何丽琴.BIM 技术在全过程工程造价管理中的应用 分析[J].中国建材科技,2015,24(03):83-84.

[2]黄慧望.BIM 技术在工程造价管理中的应用探究 [J]. 低碳世界,2016,(24):218-219.

[3]蒲红娟.BIM 技术在工程造价管理中的应用研究[D]. 郑州大学,2017,(11):53.

[4]李菲.BIM 技术在工程造价管理中的应用研究 [D]. 青 岛理工大学,2014,(04):65. 